\title{
Numerical Simulation of Influence of Changing a Dam Height on Liquid Steel Flow and Behaviour of Non-metallic Inclusions in the Tundish
}

\author{
Adam Cwudziński \\ Czestochowa University of Technology, \\ Department of Metals Extraction and Recirculation \\ Poland
}

\section{Introduction}

The steel material is formed during the course of heterophase processes. During the smelting, ladle treatment and casting of steel efforts are made to obtain a homogeneous material that is free from any type of contaminants, which include both non-metallic inclusions (NMI) and gases. Among hazardous gases causing defects in steel material are oxygen, nitrogen, or hydrogen. NMI, on the other hand, include any types of oxides, sulphides and nitrides (Nuspl et al., 2004; Rocabois et al., 2003; Van Ende et al., 2009; Herrera-Trejo et al., 1998). The current state of knowledge enables steel products to be manufactured, which meet any requirements imposed on particular steel grades. However, the constant development of technology certainly enables searching for new standards and the production of even purer steel grades than those currently manufactured in production conditions. Due to the systematically depleting iron ore deposits, the electric arc process is more and more commonly used for steel production, which relies on scrap being the main carrier of impurities that might penetrate into the structure of steel material. Therefore it seems justifiable to develop and improve the processes of ladle treatment and continuous casting of liquid steel (Matsuura et al., 2007; Tanaka et al., 1994; Lachmund \& Xie, 2003; Xie et al., 2005; Gupta \& Chandra, 2004; Basu et al., 2004). Presently, the liquid metal as prepared on the ladle furnace stand has the required metallurgical purity and temperature allowing it to be cast by the continuous method. However, a number of interesting research works concerning tundishes have drawn the metallurgists' attention to this plant and contributed to perceiving the tundish also as an effective device assisting the liquid steel refining processes (Solorio-Diaz et al., 2005; Lopez-Ramirez et al., 2001; Hou et al., 2008; Bessho et al., 1992; Kuklev et al., 2004; Cwudziński, 2010). This results primarily from the fact that liquid steel resides in the tundish for a specific time, during which any phenomena that favour the refining process can be stimulated and intensified. The present chapter reports the results of studies on the behaviour of liquid steel and NMI in liquid steel as it flows through the tundish. The Ansys-Fluent ${ }^{\circledR}$ program was used for solved mathematical model of casting process. 
Plotting of the RTD (residence time distribution) curve was possible by using a virtual tracer and introducing it to the numerical tundish model. As a result of computations, fields of liquid steel flow, fields of turbulence intensity, fields of steel temperature and nonmetallic inclusions growth, residence time distribution type $\mathrm{C}$ and $\mathrm{F}$ curves were obtained. The facility under investigation is a tundish designed for casting slabs. This is a wedgetype tundish of a nominal capacity of 30 tons. The tundish incorporates a stopper rod system for controlling the outflow of liquid steel into the mould. Two novel constructional solutions concerning the change in the tundish working space were designed for the facility under examination. The dam being presently in use was made in two variants by changing the dam height. Thus, information about the influence of dam height variation on the process of NMI growth in the liquid metal and on liquid steel flow hydrodynamics was obtained. The description of the above-mentioned phenomenon is important, because the larger non-metallic inclusions, the easier they flow out to the liquid metal surface and can be assimilated by the tundish powder. However, the NMI growth generating the change in non-metallic inclusions size alone does not guarantee that the refining process will be effective. Therefore, the selection of the type of liquid steel flow control device to enhance the NMI take-out is of key importance. The intensification of liquid steel refining processes must also have rational justification in the costs incurred for this purpose. Therefore, the making of prototype flow control devices and their application in actual industrial conditions should be preceded by simulation studies carried out for a particular industrial facility, while maintaining the main technological parameters of the process being run.

\section{Testing methodology}

\subsection{Numerical model}

The mathematical model for the flow of steel in the tundish is described in detail in work (Cwudziński, 2010). The computer simulations were performed for unsteady and nonisothermal conditions. However for the simulation of the simultaneous flow of liquid steel and non-metallic inclusions and growth and aggregation of NMI in the liquid steel, the twophase "mixture" model with population balance model in the turbulent motion condition was employed. For the description of the turbulence of liquid steel flow through the tundish, the k- $\varepsilon$ turbulence model was adopted (Ilegbusi et al., 2000). In the population balance model, discrete method was employed for simulation of non-metallic phase behaviour within the working space of the tundish. The both model are described by the following equations:

$$
\begin{gathered}
\frac{\partial}{\partial t}\left(\rho_{m}\right)+\nabla \cdot\left(\rho_{m} \vec{v}_{m}\right)=0 \\
\vec{v}_{m}=\frac{\sum_{k-1}^{n} \alpha_{k} \rho_{k} \vec{v}_{k}}{\rho_{m}} \\
\rho_{m}=\sum_{k=1}^{n} \alpha_{k} \rho_{k}
\end{gathered}
$$




$$
\begin{gathered}
\frac{\partial}{\partial t}\left(\rho_{m} \vec{v}_{m}\right)+\nabla \cdot\left(\rho_{m} \vec{v}_{m} \vec{v}_{m}\right)=-\nabla p+\nabla \cdot\left[\mu_{m}\left(\nabla \vec{v}_{m}+\nabla \vec{v}_{m}^{T}\right)\right]+ \\
\rho_{m} \vec{g}+\vec{F}+\nabla \cdot\left(\sum_{k=1}^{n} \alpha_{k} \rho_{k} K \vec{v}_{d r, k} \vec{v}_{d r, k}\right) \\
\mu_{m}=\sum_{k=1}^{n} \alpha_{k} \mu_{k} \\
\vec{v}_{d r, k}=\vec{v}_{k}-\vec{v}_{m} \\
\frac{\partial}{\partial t} \sum_{k=1}^{n}\left(\alpha_{k} \rho_{k} E_{k}\right)+\nabla \cdot \sum_{k=1}^{n}\left(\alpha_{k} \vec{v}_{k}\left(\rho_{k} h_{k}+p\right)\right)=\nabla \cdot\left(k_{e f f} \nabla T\right)+S_{E}
\end{gathered}
$$

where: $\mathrm{t}$ - time $[\mathrm{s}], \rho_{\mathrm{m}}$ - mixture density $\left[\mathrm{kg} / \mathrm{m}^{3}\right], \vec{v}_{m}$-mass averaged velocity $[\mathrm{m} / \mathrm{s}], \alpha_{\mathrm{k}}-$ volume fraction of phase $\mathrm{k}[-], \rho_{\mathrm{k}}$ - density of phase $\mathrm{k}\left[\mathrm{kg} / \mathrm{m}^{3}\right], \vec{v}_{k}$ - velocity of phase $\mathrm{k}[\mathrm{m} / \mathrm{s}]$, $\rho_{\mathrm{m}}$ - mixture density $\left[\mathrm{kg} / \mathrm{m}^{3}\right], \mathrm{p}$ - pressure $[\mathrm{Pa}], \mu_{\mathrm{m}}$ - viscosity of mixture $[\mathrm{Pa} \cdot \mathrm{s}], \mathrm{n}$ - number of phases, g - gravitational acceleration $\left[\mathrm{m} / \mathrm{s}^{2}\right], \vec{F}$ - body force $[\mathrm{N}], \vec{v}_{d r, k}$ - drift velocity of phase $\mathrm{k}[\mathrm{m} / \mathrm{s}], \mu_{\mathrm{k}}$ - viscosity of phase $\mathrm{k}[\mathrm{Pa} \cdot \mathrm{s}], \mathrm{T}$-temperature $[\mathrm{K}], \mathrm{S}_{\mathrm{E}}$ - volumetric heat sources, $\mathrm{k}_{\text {eff }}$ - effective thermal conductivity $[\mathrm{W} / \mathrm{m} \cdot \mathrm{K}], \mathrm{h}_{\mathrm{k}}$ - enthalpy for phase $\mathrm{k}[\mathrm{J} / \mathrm{kg}]$. The relative velocity and drift velocity are presented by the following expressions:

$$
\begin{gathered}
\vec{v}_{p q}=\vec{v}_{p}-\vec{v}_{q} \\
c_{k}=\frac{\alpha_{k} \rho_{k}}{\rho_{m}} \\
\vec{v}_{d r, p}=\vec{v}_{p q}-\sum_{k=1}^{n} c_{k} \vec{v}_{q k}
\end{gathered}
$$

where: $\vec{v}_{p q}$ - slip velocity $[\mathrm{m} / \mathrm{s}], \vec{v}_{p}$ - velocity of secondary phase $[\mathrm{m} / \mathrm{s}], \vec{v}_{q}$ - velocity of primary phase $[\mathrm{m} / \mathrm{s}], \mathrm{c}_{\mathrm{k}}-$ mass fraction for any phase $\mathrm{k}[-], \alpha_{\mathrm{k}}$ - volume fraction of phase $\mathrm{k}$ $[-], \rho_{\mathrm{k}}$ - density of phase $\mathrm{k}\left[\mathrm{kg} / \mathrm{m}^{3}\right], \rho_{\mathrm{m}}$ - mixture density $\left[\mathrm{kg} / \mathrm{m}^{3}\right], \vec{v}_{d r, p}$ - drift velocity $[\mathrm{m} / \mathrm{s}]$, $\vec{v}_{q k}$ - velocity of phase $\mathrm{k}[\mathrm{m} / \mathrm{s}]$.

The relative velocity and drift velocity are presented by the following expressions:

$$
\begin{gathered}
\frac{\partial}{\partial t}\left(\rho_{N M I} \alpha_{i}\right)+\nabla \cdot\left(\rho_{N M I} u_{i} \alpha_{i}\right)+\frac{\partial}{\partial V}\left(\frac{G_{v} \rho_{N M I} \alpha_{i}}{V}\right)=\rho_{N M I} V_{i}\left(B_{a g, i}-D_{a g, i}\right)+0^{i} \rho_{N M I} V_{0} \dot{n}_{0} \\
\alpha_{i}=N_{i} V_{i}, \quad i=0,1, \ldots, N-1 \\
N_{i}(t)=\int_{V_{i}}^{V_{i+1}} n(V, t) d V \\
f_{i}=\frac{\alpha_{i}}{\alpha}
\end{gathered}
$$




$$
\begin{aligned}
& \frac{\partial}{\partial V}\left(\frac{G_{v} \rho_{N M I} \alpha_{i}}{V}\right)=\rho_{N M I} V_{i}\left[\left(\frac{G_{v, i-1} N_{i-1}}{V_{i}-V_{i-1}}\right)-\left(\frac{G_{v, i} N_{i}}{V_{i+1}-V_{i}}\right)\right] \\
& B_{a g, i}=\sum_{k=1}^{N} \sum_{j=1}^{N} a_{k j} N_{k} N_{j} x_{k j} \xi_{k j} \\
& D_{a g, i}=\sum_{j=1}^{N} a_{i j} N_{i} N_{j} \\
& a_{i j}=a\left(V_{i}, V_{j}\right) \\
& \xi_{k j}=\left\{\begin{array}{c}
1 \text { for } V_{i}<V_{a g}<V_{i+1}, \text { where } i \leq N-1 \\
0 \text { otherwise }
\end{array}\right. \\
& V_{a g}=\left[x_{k j} V_{i}+\left(1-x_{k j}\right) V_{i+1}\right] \\
& x_{k j}=\frac{V_{a g}-V_{i+1}}{V_{i}-V_{i+1}}
\end{aligned}
$$

where: $\rho_{\mathrm{NMI}}$ - density of non-metallic inclusions $\left[\mathrm{kg} / \mathrm{m}^{3}\right], \alpha_{\mathrm{i}}$ - volume fraction of particle size I [-], $\alpha$ - total volume fraction of the secondary phase [-], $u_{i}$ - velocity magnitude of particle size i $[\mathrm{m} / \mathrm{s}], \mathrm{V}$ - volume $\left[\mathrm{m}^{3}\right], \mathrm{G}_{\mathrm{v}}$ - particle volume $\left[\mathrm{m}^{3}\right], \mathrm{V}_{\mathrm{i}}$ - volume of the particle size $i\left[\mathrm{~m}^{3}\right], \mathrm{B}_{\mathrm{ag}, \mathrm{i}}$ - particle size $\mathrm{i}$ birth rates of aggregation $\left[\mathrm{m}^{3} / \mathrm{s}\right], \mathrm{D}_{\mathrm{ag}, \mathrm{i}}$ - particle size i death rates of aggregation $\left[\mathrm{m}^{3} / \mathrm{s}\right], \dot{n}_{0}$ - nucleation rate [particles $\left./ \mathrm{m}^{3} / \mathrm{s}\right], \mathrm{a}_{\mathrm{ij}}$ - aggregation kernel $\left[\mathrm{m}^{3} / \mathrm{s}\right], \mathrm{V}_{\mathrm{ag}}$ - particle volume resulting from the aggregation of particle $\mathrm{k}$ and $\mathrm{j}\left[\mathrm{m}^{3}\right], \mathrm{x}_{\mathrm{kj}}-$ contribution of particle $\mathrm{k}$ and $\mathrm{j}[-], \mathrm{N}$ - number of bins.

The variation in the size of NMIs as a result of their mutual collisions caused by the turbulent motion of steel in the population balance model is expressed by the so called collision kernel $\left(\mathrm{a}_{\mathrm{ij}}\right)$ which is described by the following expressions:

$$
\begin{gathered}
a_{i j}=\boldsymbol{l}_{T} \sqrt{\frac{8 \pi}{15}} \dot{\gamma} \frac{\left(V_{i}+V_{j}\right)^{3}}{8} \\
\dot{\gamma}=\frac{\varepsilon^{0,5}}{v} \\
\boldsymbol{l}_{T}=0,732\left(\frac{5}{N_{T}}\right)^{0,242} \\
N_{T}=\frac{6 \pi \mu\left(V_{i}+V_{j}\right)^{3} \dot{\lambda}}{8 H}
\end{gathered}
$$




$$
\dot{\lambda}=\left(\frac{4 \varepsilon}{15 \pi v}\right)^{0,5}
$$

where: $l_{T}$ - capture efficiency coefficient of turbulent collision, $\dot{\gamma}$ - shear rate, $\varepsilon$ - turbulent energy dissipation rate $\left[\mathrm{m}^{2} / \mathrm{s}^{3}\right], v$ - kinematic viscosity $\left[\mathrm{m}^{2} / \mathrm{s}\right], \mathrm{N}_{\mathrm{T}}-$ ratio between viscous force and Van der Waals force, $\dot{\lambda}$ - deformation rate, $\mathrm{H}$ - Hamaker constant for non-metallic inclusions 2,3·10-20.

To build the virtual tundish models with an appropriate computational grid, Gambit software was used. The space of the virtual tundish models was formed by a computation grid made of 575-585 thousand tetrahedral elements. Tet/hybrid elements of Tgrid type were used to generate the computational grid. The grid made form such elements consisted primarily of tetrahedrons; but it could also contain cubes, pyramids and wedges. Computations of the flow of steel and NMIs (non-metallic inclusions) were performed in the Ansys-Fluent ${ }^{\circledR}$ program. Liquid steel flowed into the tundish at a velocity of $1.31 \mathrm{~m} / \mathrm{s}$. The values of $\mathrm{k}$ and $\varepsilon$ for the steel flowing into the tundish were, respectively: $0.017161 \mathrm{~m}^{2} / \mathrm{s}^{2}$ and $0.064231 \mathrm{~m}^{2} / \mathrm{s}^{3}$. The temperature of the liquid metal flowing into the tundish was 1827 $\mathrm{K}$. The symmetry condition was assumed on the free surface of steel, whereas on the remaining surfaces describing the tundish and flow control device walls, the wall condition was assumed. No heat losses was assumed on the surface described by the symmetry condition, by assuming the ideal thermal insulation of the liquid metal. The heat loss on the tundish walls and bottom was assumed to be $2600 \mathrm{~W} / \mathrm{m}^{2}$, and on the flow control device wall describing surfaces and the immersible poring tube surfaces, $1750 \mathrm{~W} / \mathrm{m}^{2}$. For the description of the non-metallic phase, non-metallic inclusions of a density of $3960 \mathrm{~kg} / \mathrm{m}^{3}$ were selected. The heat capacity and thermal conductivity of NMIs and liquid steel were, respectively: $1364 \mathrm{~J} / \mathrm{kg} \cdot \mathrm{K}$ and $5,5 \mathrm{~W} / \mathrm{m} \cdot \mathrm{K}$, and $750 \mathrm{~J} / \mathrm{kg} \cdot \mathrm{K}$ and $41 \mathrm{~W} / \mathrm{m} \cdot \mathrm{K}$. In addition, to describe the effect of temperature on the liquid steel, Bussinesq's description was used. For the employed description, the thermal expansion for steel was assumed to be at a level of $0,0001 \mathrm{~K}^{-1}$. For the computation of tundish steel residence time curves, the scalar transfer equation, so called UDS user defined scalar, was used. It was thereby possible to introduce a virtual tracer to the system under analysis and to take the measurement of the variation of tracer concentration on the tundish outlet in time. Based on industrial experimental tests, the boundary conditions of the mathematical model were defined and an overall picture of non-metallic inclusion behaviour under industrial conditions was obtained. It was assumed in the simulation studies that the initial distribution in the form of $1,1,2,1,4,1,7,2,2,5,3,3,6$, $4,3 \mu \mathrm{m}$ diameter NMI fraction shares on the tundish inlet was, respectively: $0,55,0,088$, $0,088,0,088,0,088,0,088,0,0033,0,0033$ and 0,0033 . Variation in the share of NMI fractions in the size range from 1 to $11 \mu \mathrm{m}$, i.e. NMI diameters of $1,1,2,1,4,1,7,2,2,5,3,3,6,4,3,5,2,6,3$, $7,6,9,1$ and $11 \mu \mathrm{m}$, was observed during computer simulation. In all of the simulation variants, only the possibility of NMI aggregation due to turbulence collisions was assumed. The system of equations forming the mathematical model of liquid steel flow with nonmetallic inclusions secondary phase was solved by the method of control volumes by employing discretization of the second order upwind using the sequential solver. On the other hand "Quick" discretization was used for volume fraction. The algorithm SIMPLEC (Semi-Implicit Method for Pressure-Linked Equations-Consistent) was used for the description of the coupling of the pressure and velocity fields in the model being solved. The controlled level of residues was at a level of at least $10^{-3}$. The condition to comply with the impassable $\mathrm{y}^{+}$parameter values $(30 \div 60)$ indicating the correct choice of the grid in the 
wall boundary layers was also respected. The numerical computations were made with a so called 3ddp three-dimensional double precision solver. The simulations of steel flow in the tundish furnishing variants under consideration were performed on two 64-bit computational servers, each of them being equipped with two quad core $2.4 \mathrm{GHz}$ processors and an operating memory of 12 GB RAM. The assessment of flow can already be done at the stage of analysis of the graphic distribution of the RTD curve E and F (qualitative analysis). From the obtained E-type time curve distributions, it is possible to determine the values that quantitatively define the hydrodynamic conditions in the tundish (Sahai \& Emi, 2008; Mazumdar \& Guthrie, 1999). Thus, the ranges of the stagnant, plug, and ideal mixing flows can be determined. In this method, the stagnant flow occurs in the regions, for which the value of the dimensionless time of steel residence in the tundish exceeds the value of 2 . While, the plug flow is the sum of the values of the first and the maximum times of tracer appearances on the tundish nozzle divided by two. The plug flow is most favourable for the free NMI flotation from the liquid steel, whereas the stagnant flow may lead to drops in liquid steel temperature below the level permissible for a specific steel grade. In turn, the $\mathrm{F}$ curve is essential for the determination of the range of the transient zone that characterizes the hydrodynamic conditions existing in the tundish during the successive casting of steel grades differing in chemical composition. In the transient zone, these is a batch of liquid metal with a composition in between those of the steel grades being cast. Hence, this is a product which is difficult to be classified and subsequently processed in the Rolling Mill's departments. The model presented in work [Clark et al.] assumes that the transient zone exist between the values 0.2 and 0.8 of the dimensionless concentration of the tracer substance used for recording the curve in the system under examination. The F curve is described by relationship 27.

$$
F=\frac{C_{t}-C_{0}}{C_{\infty}-C_{0}}
$$

where: $\mathrm{C}_{0}$ - initial concentration of chemical element $[\mathrm{kg}], \mathrm{C}_{t}$ - temporary concentration of a chemical element [kg], $\mathrm{C}_{\infty}$ - final concentration of a chemical element [kg].

\subsection{Characterization of the test facility}

The test object is a tundish designed for casting concast slab (fig.1a). Figure 1b shows the virtual geometry of the tundish with a line plotted, which indicates the distance by which the dam has been moved away from the tundish pouring zone. The nominal tundish capacity is 30 tons, but in the simulation variants examined it contained $25 \mathrm{Mg}$. This is a wedge-type tundish with a characteristic lowering of the bottom in the tundish stopper rod zone (the steel level in the tundish stopper rod zone is $0,92 \mathrm{~m}$, and in the remaining tundish space, $0,7 \mathrm{~m}$ ). Steel flows to the tundish through a ceramic ladle shroud of an inner diameter of $70 \mathrm{~mm}$. In the tundish being currently operated in the industrial conditions, a notched dam and a system for controlling the flow of steel to the mould (stopper rod) have been mounted. The dimensions of the dam are shown in figure 2. The liquid steel flows to the mould through a ceramic submerged entry nozzle of an inner diameter of $70 \mathrm{~mm}$.

For the modification of the direction of liquid steel flow within the tundish working space, a modified dam was employed, which is currently being used industrially. The modification of the dam consisted in the change of its height. In the first modification variant, the dam was elongated by $0,23 \mathrm{~m}$ up to $0,35 \mathrm{~m}$, while in the second variant, by $0,38 \mathrm{~m}$ up to $0,5 \mathrm{~m}$. Should favourable results from the point of view of conducting the CSC technology be 
obtained, the proposed dam modification would be very simple to accomplish in the industrial conditions. The proposed change of the dam height does not need any interference in the design of the tundish working space. On the other hand, the modification involves an increase in the surface exposed to the liquid metal. Therefore, the modified dam should be made from refractory materials that will prevent any erosion from occurring during the casting process.

a)

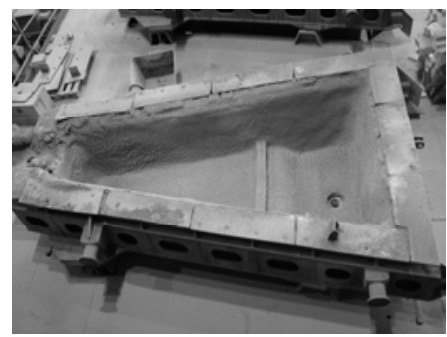

c)

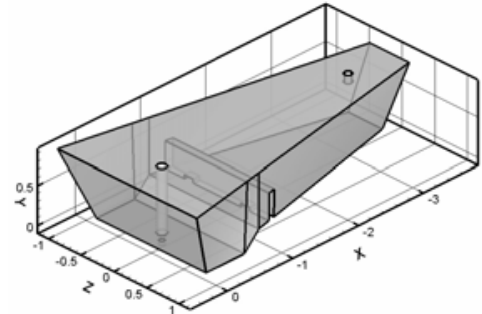

b)

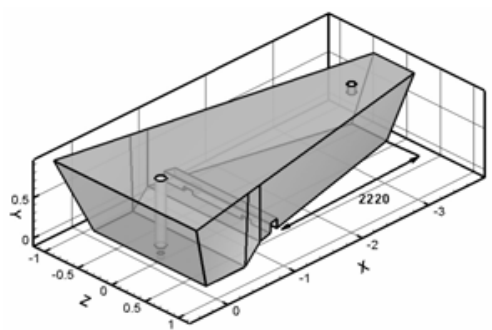

d)

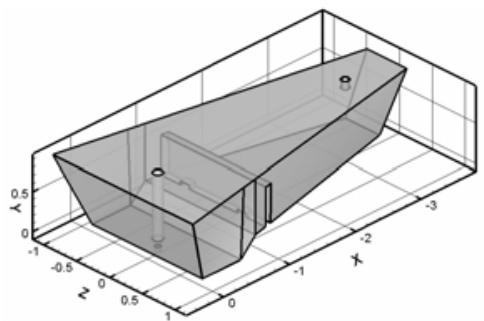

Fig. 1. Views of test facility: a) real tundish, b) virtual model of tundish with low dam, c) virtual model of tundish with medium dam, d) virtual model of tundish with high dam

a)

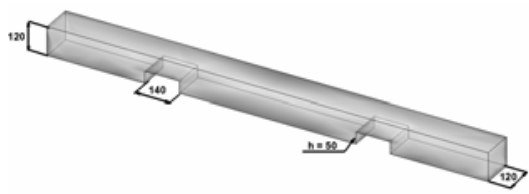

b)

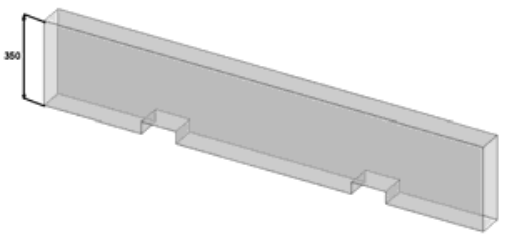

c)

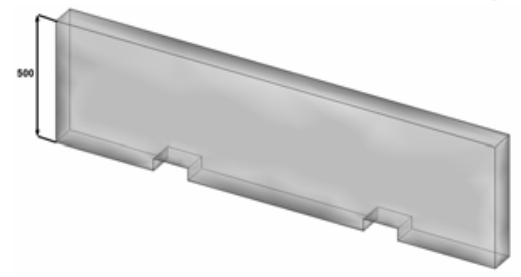

Fig. 2. Views of dam: a) low dam, b) medium dam, c) high dam 


\subsection{Description of industrial experiment}

The industrial experiment was aimed at verifying the steel flow hydrodynamics, as well as the distribution of non-metallic inclusions in the steel. For the verification of the computer simulation results for steel flow, the measurement of chemical composition of the steel was employed, whereby so called lollipop samples were taken from the CSC machine mould. The measurements were taken from the moment of opening until the moment of closing the steelmaking ladle with a steel grade other than that existing in the tundish. Using a sampler, the operator sucked in liquid steel which, after solidification, was transferred to a quantometer where the steel was assayed for chemical composition. The samples were taken, on the average, every 1 minute (the first 9 samples) and every 3 minutes (the subsequent samples), depending on the casting speed (Cwudziński, 2008). Whereas, for the verification of non-metallic inclusion distribution in the liquid steel in the tundish during the CSC process, samples of the same type were taken from the upper part of the liquid metal under the tundish powder layer. The sampling area is indicated by the broken line in Figure 3. To define the initial conditions in the numerical model for NMI inclusion distribution in the liquid steel, lollipop samples were also taken from the steelmaking ladle located at the ladle furnace stand. A sample was taken from the steel prepared for casting immediately prior to the ladle departure from the ladle furnace stand. All the samples taken, after being freely cooled down, were prepared in the form of microsections for analysis on a scanning microscope to determine the distribution of NMIs and to measure their size in the metal batch taken. The measurement area on the prepared microsection surface was a surface area of $0.8 \mathrm{~mm}^{2}$. The industrial experiments were made during a sequence of casting $1500 \times 225$ dimension concast slabs at a speed of $0.9 \mathrm{~m} / \mathrm{min}$.

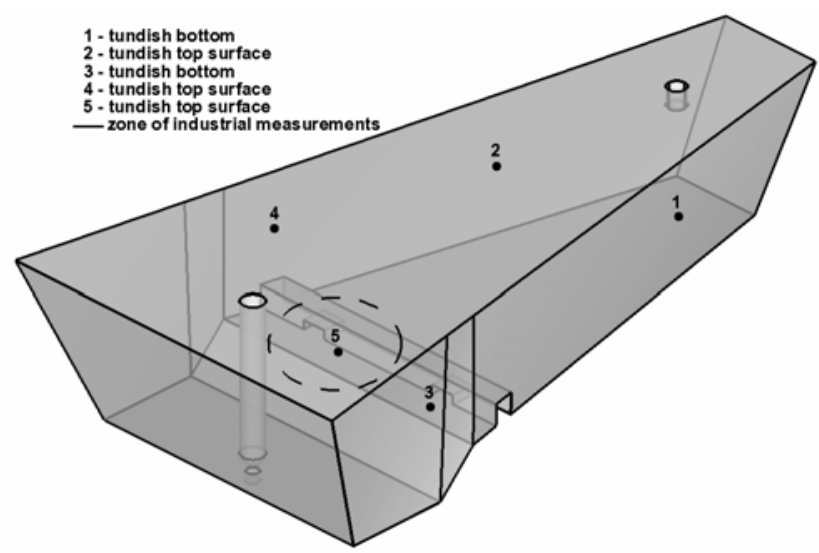

Fig. 3. View of tundish with measurement points and zone of industrial measurements

Figure 4 presents steel mixing curves for two melts differing in chemical composition, cast consecutively one after another. By recording the variation in the concentration of copper, niobium, carbon and chromium, points characterizing the process of steel mixing under real industrial conditions were obtained. The obtained industrial experiment results indicate satisfactory agreement between the computation results and the hydrodynamic conditions occurring during the course of the actual CSC process. 
a)

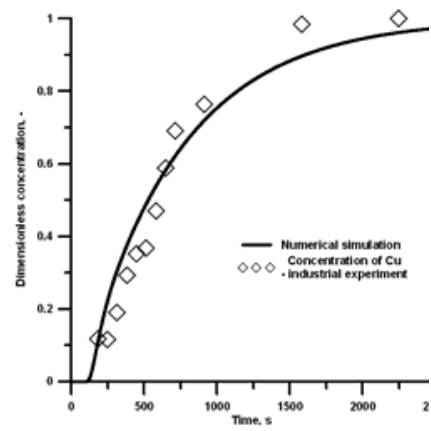

b)

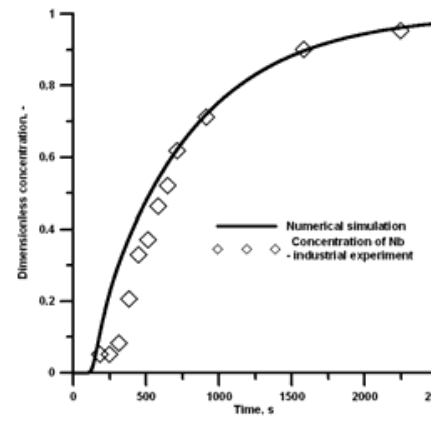

c)

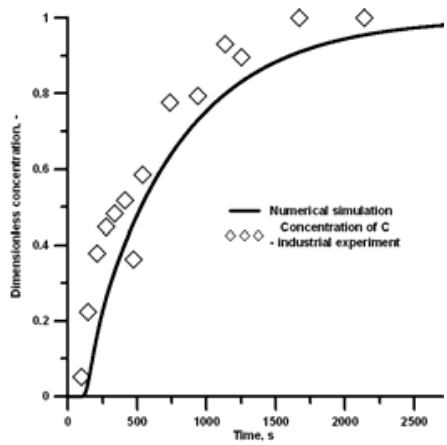

d)

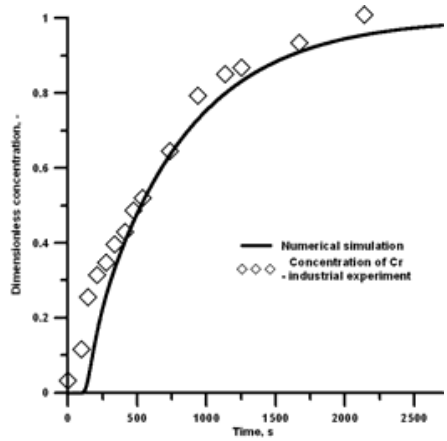

Fig. 4. Results of numerical simulation and industrial experiment: a) mixing curve calculated by numerical simulation and concentration of $\mathrm{Cu}$ measured during industrial experiment, $\mathrm{b}$ ) mixing curve calculated by numerical simulation and concentration of $\mathrm{Nb}$ measured during industrial experiment, c) mixing curve calculated by numerical simulation and concentration of $\mathrm{C}$ measured during industrial experiment, $\mathrm{d}$ ) mixing curve calculated by numerical simulation and concentration of $\mathrm{Cr}$ measured during industrial experiment

Figure 5 presents NMI growth curves computed numerically and juxtaposed with the industrial experiment results for three NMI size classes. The first size class concerned NMIs of a diameter of $1 \mu \mathrm{m}$; the second NMI size class comprised non-metallic inclusions in the size range from 1 to $3 \mu \mathrm{m}$; and the third NMI size class concerned non-metallic inclusions in the size range from 3 to $5 \mu \mathrm{m}$. The division of NMIs into size classes was due to the fact that in the real industrial conditions non-metallic inclusions occur in very diverse size ranges, e.g. in the range from 1 to $2 \mu \mathrm{m}$ there occur NMIs of a size of 1,1,1,1,15 or 1,2 and 1,5 $\mu \mathrm{m}$, etc., up to $2 \mu \mathrm{m}$. In the computer simulation, Class I was represented by NMIs of a size of 1 $\mu \mathrm{m}$; Class II, by NMIs of a size of 1,2, 1,4, 1,7, 2 and $2.5 \mu \mathrm{m}$; while Class III, NMIs of a size of $3,3,6$ and $4,3 \mu \mathrm{m}$. The NMI identification made on the basis of samples taken under industrial conditions showed that there were very few NMIs of a diameter above $5 \mu \mathrm{m}$ : on the average, 2 inclusions in the area examined, i.e. in a surface area of $0.8 \mathrm{~mm}^{2}$. In several samples, no NMIs of a size above $5 \mu \mathrm{m}$ were observed at all. Hence, Figure 5 concerns the three NMI size classes. In the numerical model, the possibility of NMI growth as a result of turbulent collisions was assumed. From the obtained results, no satisfactory agreement between the computer simulation results and the industrial experimental test results is 
observed, especially for NMI size classes I and II. The numerical model does not foresee such a sharp change in NMI size from class I to class II, however it fairly well correlates with the results for class III of NMI size. The presented results indicate that the numerical model for NMI growth requires further improvement. Nevertheless, considering the complexity of the process of NMI growth in liquid steel and the difficulties involved with industrial tests (the high temperature of the CSC process), the proposed model can presently be used for the preliminary assessment of the influence of the flow control devices (FCD) on the process of NMI growth in the tundish.

a)

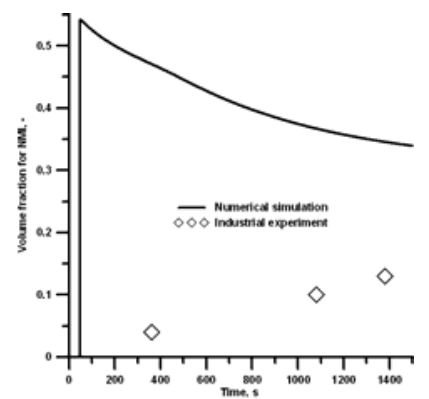

b)

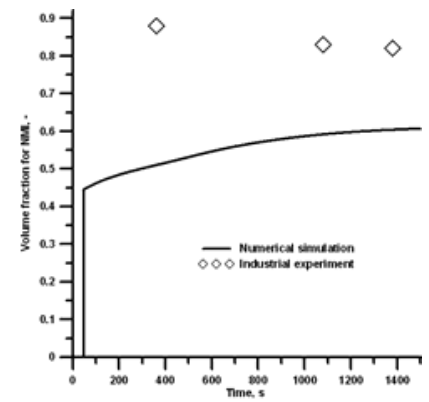

c)

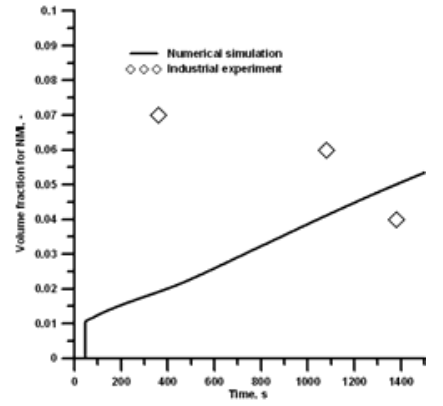

Fig. 5. Results of numerical simulation and industrial experiment: a) NMI growth curve calculated by numerical simulation and contribution of NMI (first class) in the liquid steel measured during industrial experiment, b) NMI growth curve calculated by numerical simulation and contribution of NMI (second class) in the liquid steel measured during industrial experiment, c) NMI growth curve calculated by numerical simulation and contribution of NMI (third class) in the liquid steel measured during industrial experiment

\section{Computational results}

Based on the performed computations, the fields of flow, turbulence intensity and steel temperature, among other things, have been obtained. Figure 6 presents the fields of steel flow in the central part of the tundish between the feed zone and the stopper rod system zone. When examining the presented figures it can be noticed that the change of the dam height does not cause any significant changes in the direction of steel flow in this tundish part. The tundish is divided into two regions. In the first region, between the tundish feed zone and the dam, metal circulations are observed in the central tundish part at the bottom. A back stream flowing in to this region from the stopper rod system zone can also be seen. 
Whereas, in the second tundish region, after the dam, the steel stream makes its way toward the nozzle. In all of the tundish equipment variants, there are no ascending streams in the tundish region examined, which would intensify the flotation of NMIs to the slag phase. The reconstruction of the tundish does not cause any changes in the intensity of turbulence of the flowing steel (Fig. 7). The turbulence intensity is calculated from relationship (28) and take on values from 0 to 1 .

$$
I=\frac{\sqrt{\frac{2}{3}} k}{v_{r e f}}
$$

where: $v_{\text {ref }}$ - reference velocity $[\mathrm{m} / \mathrm{s}], \mathrm{k}$ - kinetic energy of turbulence $\left[\mathrm{m}^{2} / \mathrm{s}^{2}\right]$

Beyond the tundish feed zone, the turbulence intensity assumes values at a level of 0,01 , which is indicative of a calm steel flow pattern. An parameter important from the SCS process viewpoint is liquid steel temperature. Each steel grade requires a specific casting temperature, and it is therefore important to assure that the proposed modernization of the plant's inner space will not impair the thermal conditions existing in the tundish. From the results represented in Figure 8, very good thermal stability of the plant is observed in all of the tundish equipment variants proposed. Figure 9 presents the residence time curves, C and $\mathrm{F}$. The observation of hydrodynamic conditions prevailing in the tundish is possible thanks to the recording of tracer concentration variation as a function of time. On the axis of abscissae in Figure 9, the dimensionless time is expressed by the ratio of the actual time to the average tundish steel residence time. The steel movement maps, presented earlier, did not indicate any significant steel flow modification that might have been caused by the change of the dam height. Whereas, the shape of the RTD curves $C$ and F describing the flow of steel on a macro scale, that is for the entire facility, does indicate a change in the steel flow pattern for particular tundish equipment variants. The increase in dam height causes a shift of the $\mathrm{C}$ curve peak from the axis of ordinates, which results in an increase in the share of plug flow in the overall flow structure. Moreover, a shortening of the line denoting the change of tracer concentration behind the peak is observed, which will be reflected in the developing of the extent of the stagnant flow share. Changes in the flow pattern are also visible in Figure 10b, as the position of the mixing curves changes at points 0,2 and 0,8 of the dimensionless tracer concentration.

a)

b)
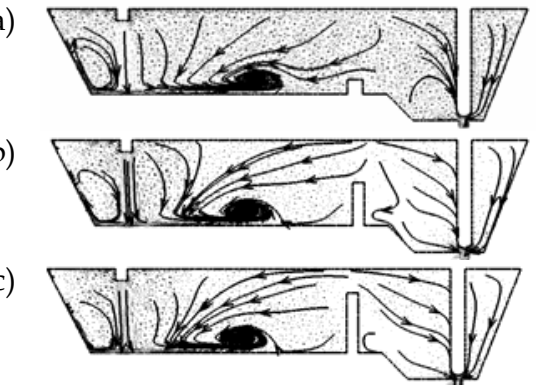

Fig. 6. Liquid steel flow in the central plane: a) tundish actually working in the steel plant, b) tundish with medium dam, c) tundish with high dam 
a)

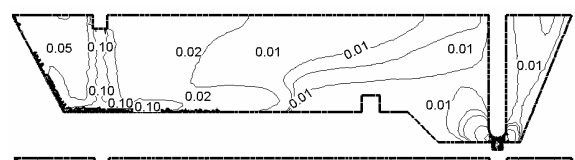

b)

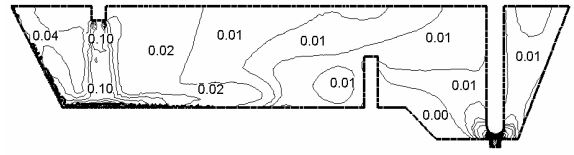

c)

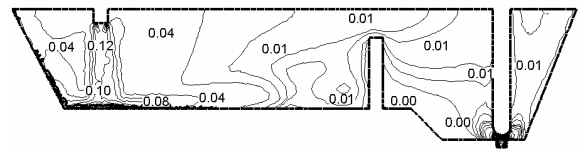

Fig. 7. Turbulence intensity of liquid steel in the central plane: a) tundish actually working in the steel plant, b) tundish with medium dam, c) tundish with high dam

a)

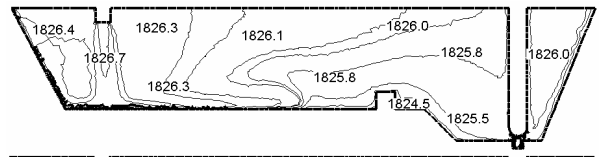

b)

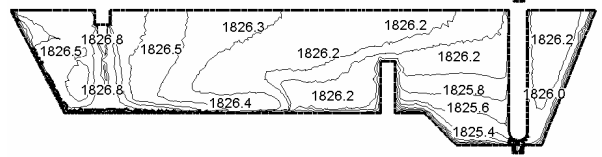

c)

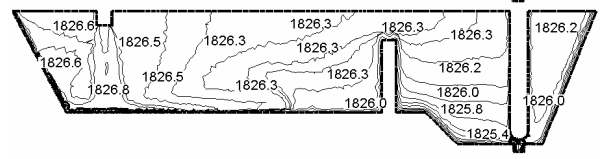

Fig. 8. Distribution of temperature fields of liquid steel in the central plane: a) tundish actually working in the steel plant, b) tundish with medium dam, c) tundish with high dam

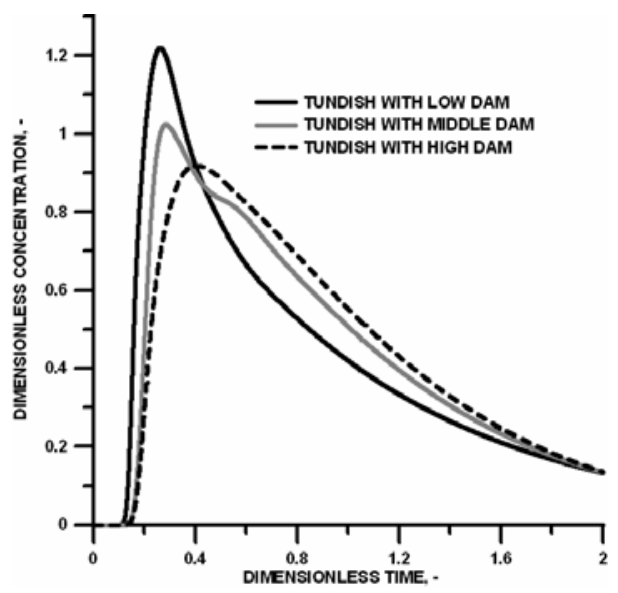

Fig. 9. Residence time distribution curve for consider variants of tundish 


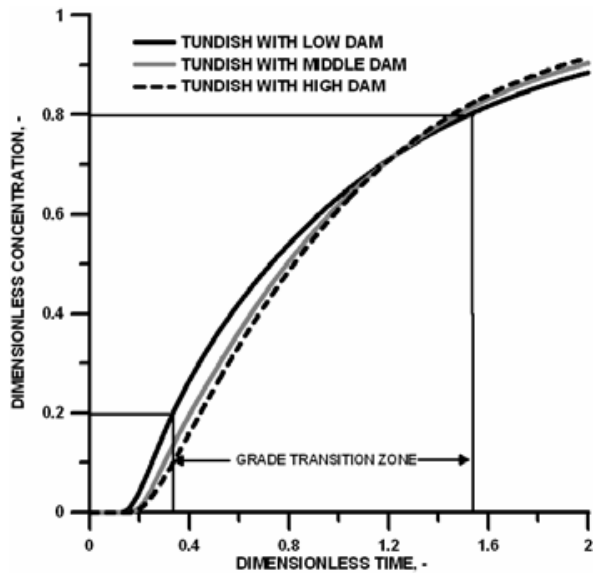

Fig. 10. Mixing curve for consider variants of tundish

For the quantitative analysis of the hydrodynamic conditions, it is necessary to calculate the shares of stagnant, plug and ideal mixing flows, as well as the quantity of metal existing in the transient zone. Table 1 provides the shares of particular flows, as calculated based on the C RTD curve. A successive increase in the dam height results in an increase in the plug flow share by $7 \%$ for the tundish with a high dam. In the case of the stagnant flow in the tundish with a high dam, a decrease in the share of this flow by $11 \%$ occurs. A positive effect of dam height change by up to $0.5 \mathrm{~m}$ is also visible for the transient zone extent. For this variant of tundish equipment, there is by $5 \mathrm{Mg}$ less steel in the transient zone compared to the tundish variant being currently used in the industrial conditions.

\begin{tabular}{|c|c|c|c|}
\hline \multirow{2}{*}{$\begin{array}{c}\text { No. of } \\
\text { tundish } \\
\text { variant }\end{array}$} & Stagnant flow & Plug flow & Ideal mixing flow \\
\cline { 2 - 4 } & 33,3 & 13,2 & 53,5 \\
\hline 1 & 26,2 & 14,2 & 59,6 \\
\hline 2 & 22,4 & 20,2 & 57,4 \\
\hline 3 & &
\end{tabular}

Table 1. Steel flow characteristic for consider variants of tundish

\begin{tabular}{|c|c|c|c|c|}
\hline $\begin{array}{c}\text { No. of } \\
\text { tundish } \\
\text { variant }\end{array}$ & $\begin{array}{c}\text { Range of } \\
\text { transition } \\
\text { zone, }[\mathrm{s}]\end{array}$ & $\begin{array}{c}\text { Length of casting } \\
\text { steel } \\
\text { strand, }[\mathrm{m}]\end{array}$ & $\begin{array}{c}\text { Weight of casting } \\
\text { steel strand, }[\mathrm{Mg}]\end{array}$ & $\begin{array}{c}\text { Reduction of } \\
\text { grade transition } \\
\text { zone, }[\mathrm{Mg}]\end{array}$ \\
\hline 1 & 871 & 13,06 & 30,8 & - \\
\hline 2 & 778 & 11,67 & 27,5 & 3,3 \\
\hline 3 & 729 & 10,93 & 25,7 & 5,1 \\
\hline
\end{tabular}

Table 2. Characterization of grade transition zone for consider variants of tundish

Figures 11 to 16 represent the curves of fraction share change for NMIs of a diameter of 1 , $2,5,3,6,5,2,7,6$ and $11 \mu \mathrm{m}$. As NMIs in the size range of 1 to $11 \mu \mathrm{m}$ primarily follow the 
liquid metal current, and their floatation onto the free steel surface depends chiefly on the steel flow direction, therefore the behaviour of NMIs in the liquid steel is represented during the average time of liquid metal residence in the tundish. For the metallurgical facility under consideration, the average liquid steel residence time, as expressed by the ratio of the mass of metal $(\mathrm{kg})$ in the tundish to the flow rate of steel $(\mathrm{kg} / \mathrm{s})$, was 740 seconds. The change in the share of particular NMI fractions reflects the NMI growth process in the liquid metal. The NMI growth process was recorded at five measurement points located within the tundish and one point located at the tundish outlet. The results of computer simulation of NMI behaviour in the steel, shown in Figures 11 to 16, excellently not only depict the steel NMI growth process itself, but also illustrate their movement within the tundish working space. This is indicated by the shift of the fraction share change curves from the axis of ordinates, depending on the measurement point. The farther away from the tundish feed zone a point is situated, the later NMIs flow in there and the recording of their growth process occurs. An exception is the third point located behind one the notches in the dam. Here, NMIs appear latest, which is indicative of the complexity of the steel flow process. The position of curve peaks shown in Figures 11-16 illustrates also how NMIs start to change their size in the first steel casting phase ( 3 minutes from the start of the casting sequence). For NMIs of a size of $1 \mu \mathrm{m}$, the value of the peak at successive measurement points is at different level in the axis of ordinates, decreasing successively. For NMIs of a diameter of 2,5, 3,6, 5,2, 7,6 and $11 \mu \mathrm{m}$, on the other hand, the curve peak attains a higher value at successive measurement points. After about 3 minutes, a stabilized NMI growth follows. For NMIs of a size above $5.2 \mu \mathrm{m}$, or the 7,6 and $11 \mu \mathrm{m}$-diameter NMIs, the share of fractions is contained in the range, successively, from $1 \mathrm{e}-4$ to $5 \mathrm{e}-11$ and from $1 \mathrm{e}-$ 3 to $3 \mathrm{e}-11$, which suggest a very slow process of NMI growing up to sizes of around 7,6 and $11 \mu \mathrm{m}$. The obtained picture refers to the testing results obtained from industrial experiment. Moreover, in the case of 7,6 and $11 \mu \mathrm{m}$-size NMIs, the fraction share values are so small that the shape of the curves representing variations in the share of fractions, as observed in Figures 15 and 16, has no significance for the NMI growth process. The change in the dam height influences the NMI aggregation process. The higher the dam, the smaller the share of $1 \mu \mathrm{m}$-diameter NMI fractions is, especially behind the dam towards the tundish outlet. The increase in the dam height intensifies the process of formation of increasingly large NMIs (Figs. 12-14). The most dynamic growth process of all NMIs examined was observed for NMIs of a diameter of $3.6 \mu \mathrm{m}$ (Fig. 12). The presented fraction share variation curves for particular NMIs, as recorded in different tundish regions, indicate little differences in the progress of the NMI growth process in a given size range. On the other hand, the observation of the NMI growth process in different tundish regions is important from the point of view of understanding of the behaviour of NMIs in different tundish regions. NMIs not assimilated by the tundish powder reach, together with steel, the tundish outlet and constitute a potential source of faults likely to occur in the concast slab. When examining the fraction share variation curves recorded at the tundish outlet, shown in Figures 11-16, one can notice that, in spite of the NMI growth process occurring in the liquid steel flowing into the mould, $1 \mu \mathrm{m}$-diameter NMIs still constitute the vast majority of the NMI population. At the same time, a greater number of larger NMIs appear in the steel flowing to the mould, e.g. for 3,6 $\mu$ m-diameter NMIs, an increment in the fraction share at a level of $100 \%$ takes place. 
a)

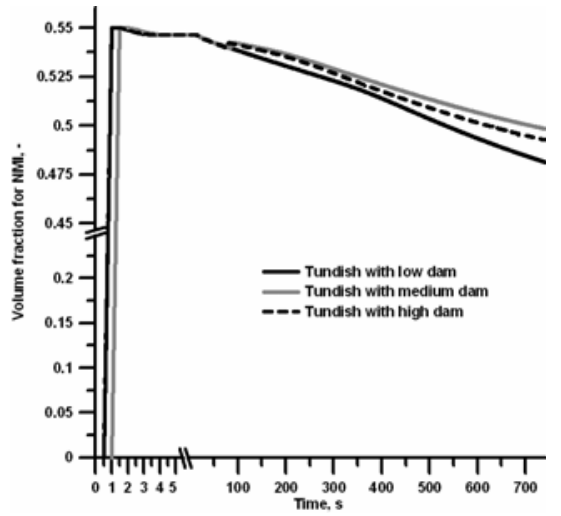

b)

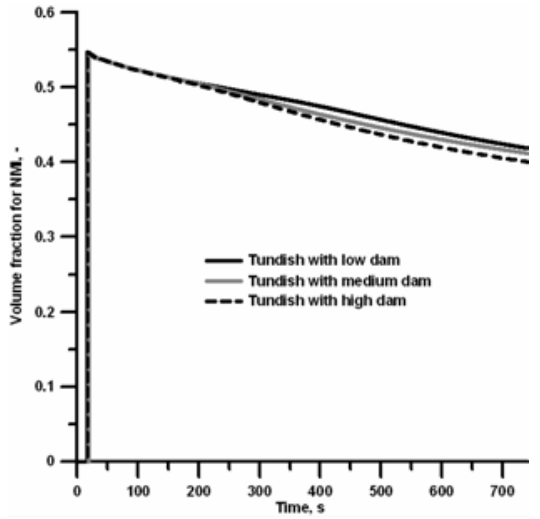

c)

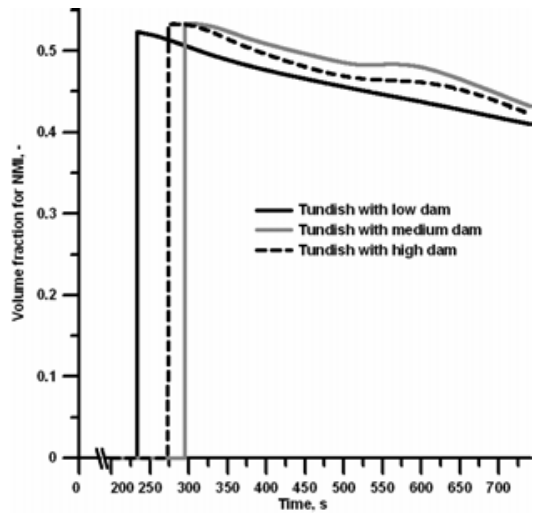

d)

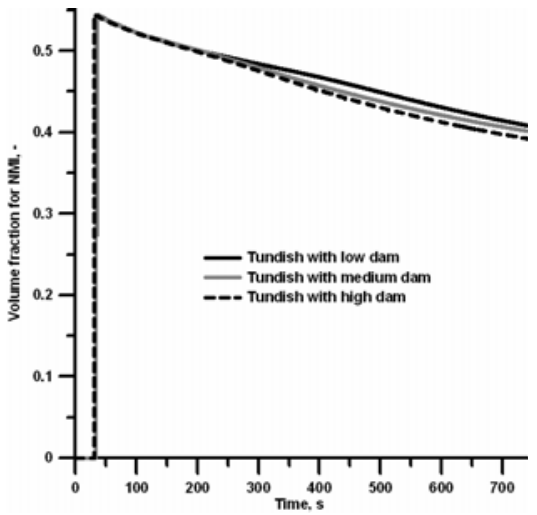

e)

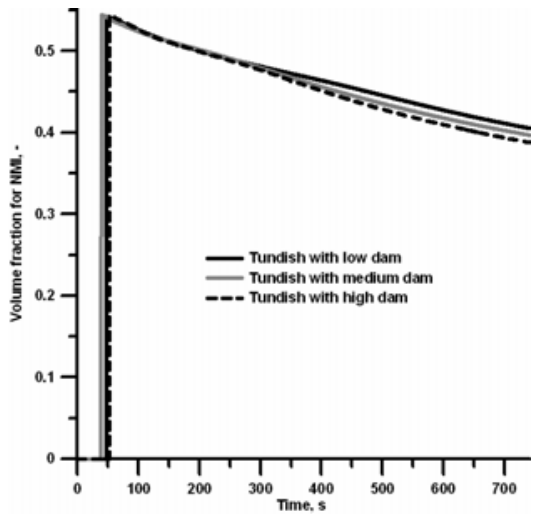

f)

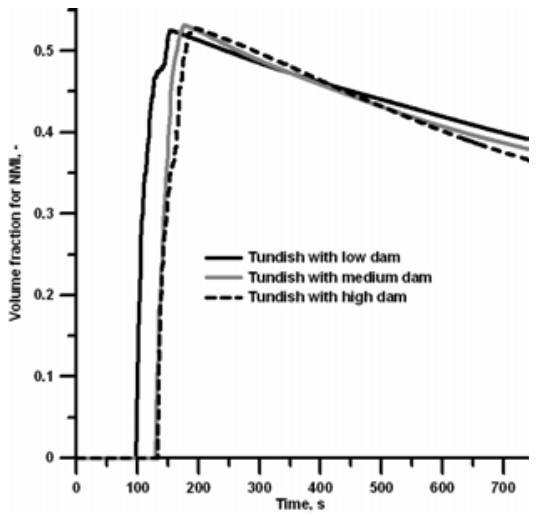

Fig. 11. NMI growth curve for $1 \mu \mathrm{m}$ diameter inclusions: a) point $1, \mathrm{~b}$ ) point 2 , c) point 3 , d) point 4, e) point 5, f) tundish outlet 
a)

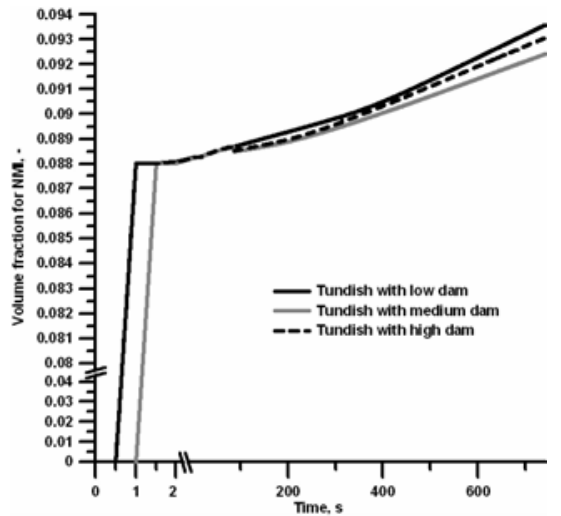

b)

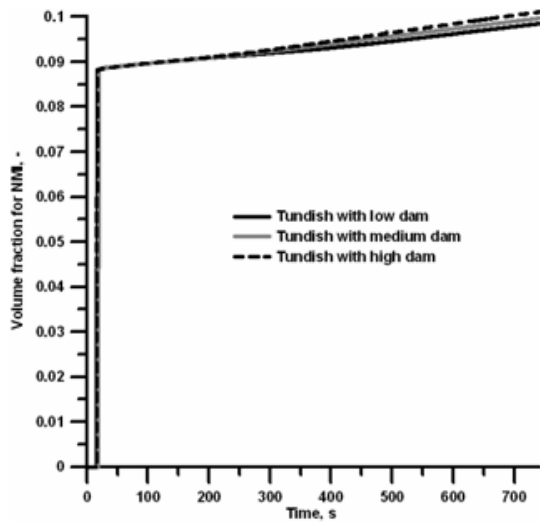

c)

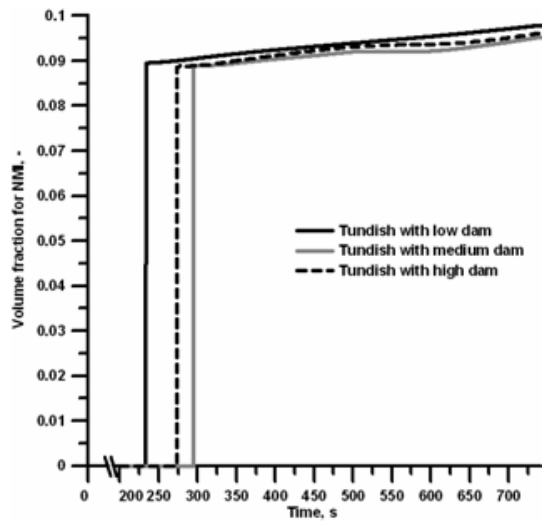

d)

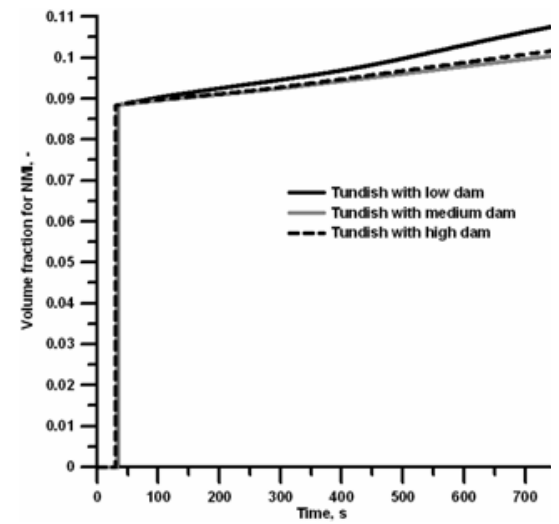

e)

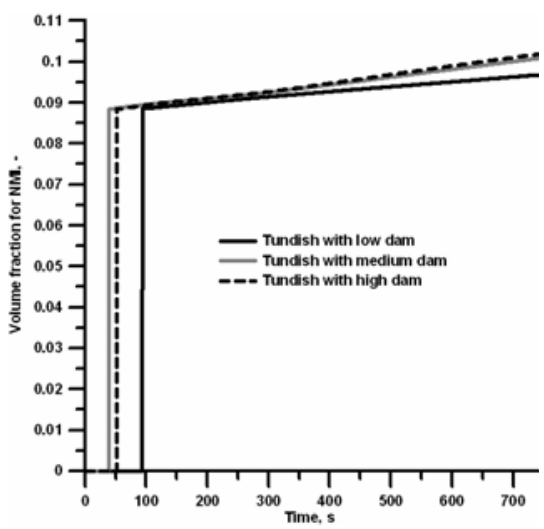

f)

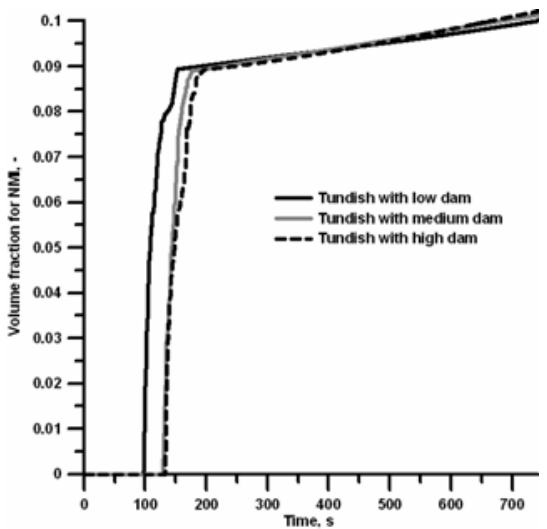

Fig. 12. NMI growth curve for $2,5 \mu \mathrm{m}$ diameter inclusions: a) point $1, \mathrm{~b})$ point $2, \mathrm{c}$ ) point 3 , d) point 4 , e) point 5, f) tundish outlet 
Numerical Simulation of Influence of Changing a Dam Height on Liquid Steel Flow and Behaviour of Non-metallic Inclusions in the Tundish

a)

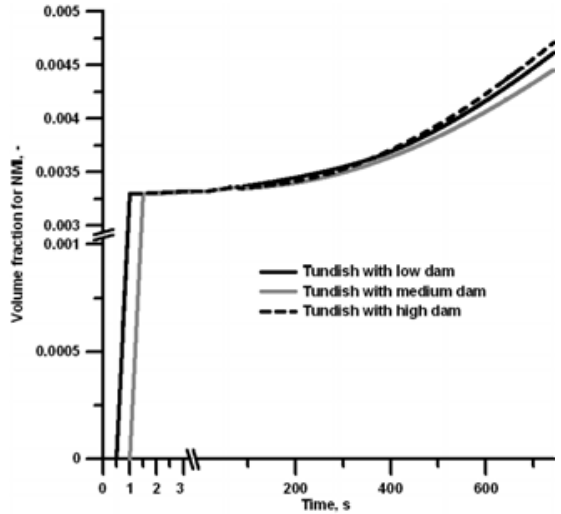

b)

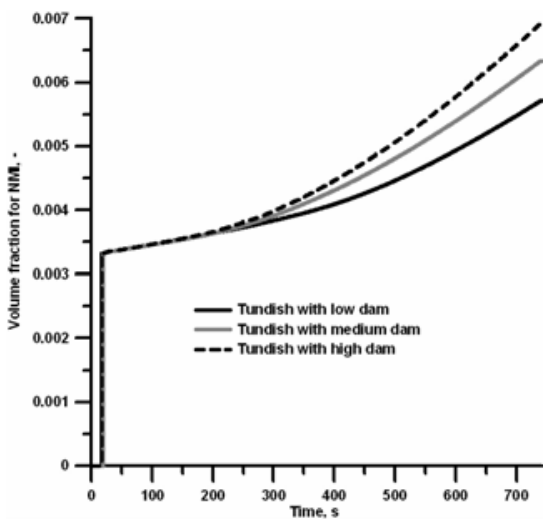

c)

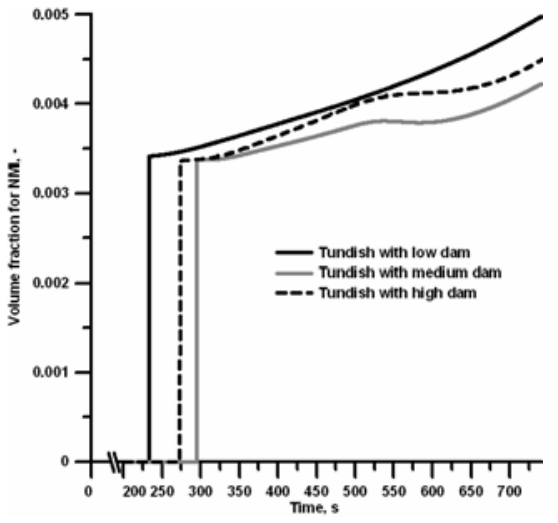

d)

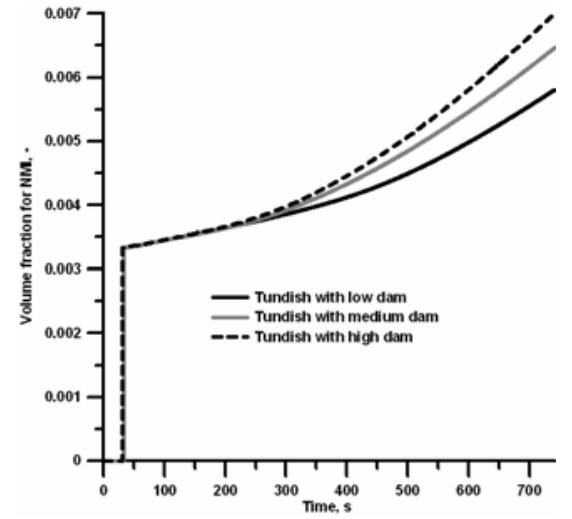

e)

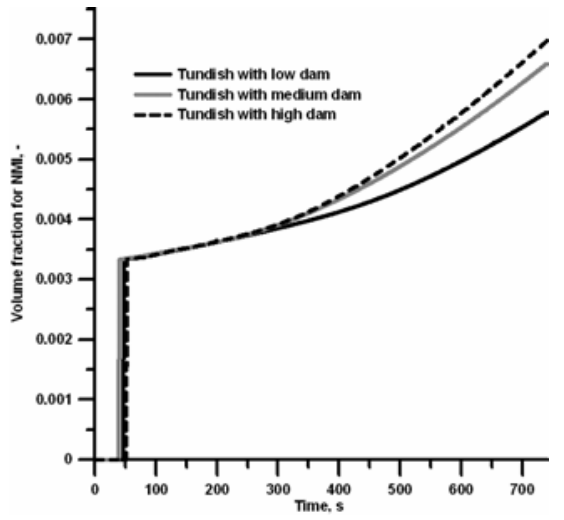

f)

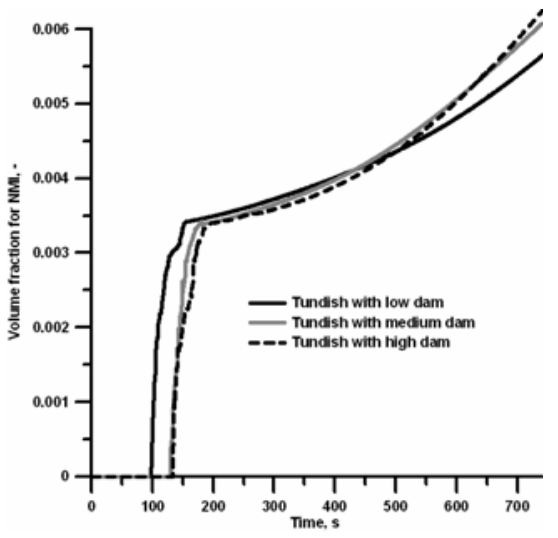

Fig. 13. NMI growth curve for $3,6 \mu \mathrm{m}$ diameter inclusions: a) point $1, \mathrm{~b})$ point $2, \mathrm{c}$ ) point 3 , d) point 4 , e) point 5, f) tundish outlet 
a)

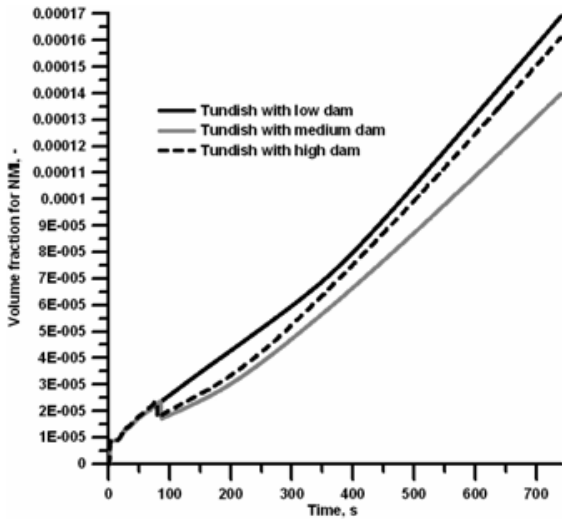

b)

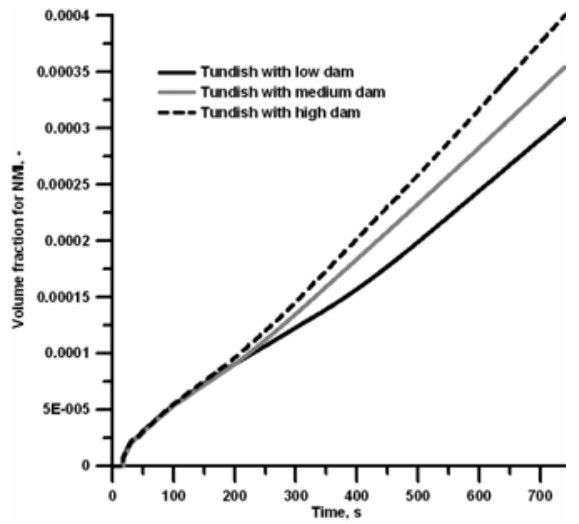

c)

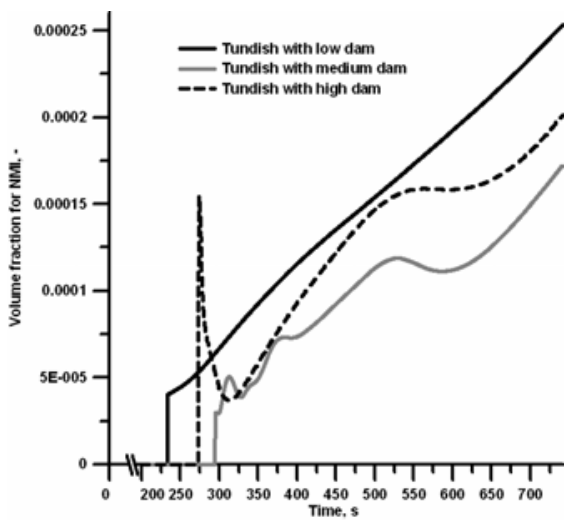

d)

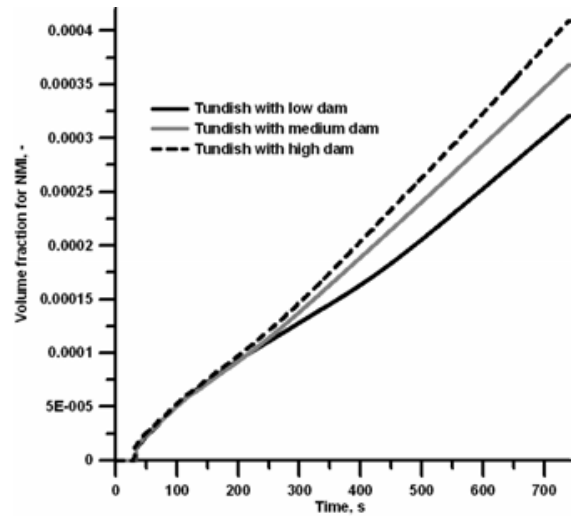

e)

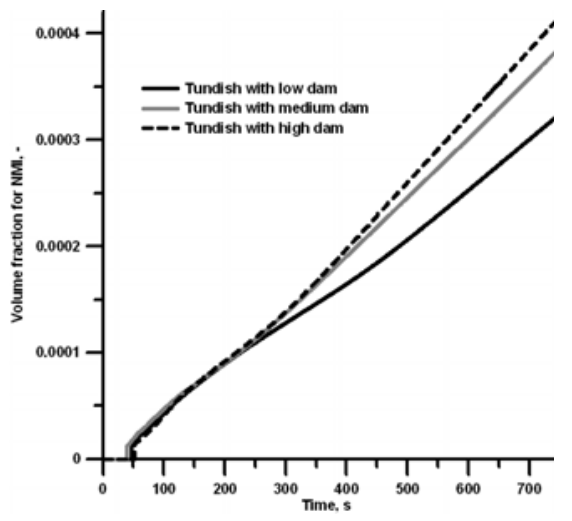

f)

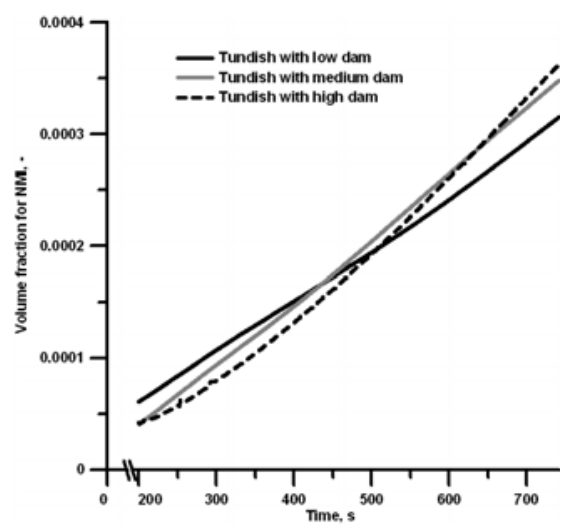

Fig. 14. NMI growth curve for 5,2 $\mu$ m diameter inclusions: a) point $1, b)$ point $2, \mathrm{c}$ ) point 3 , d) point 4 , e) point 5, f) tundish outlet 
Numerical Simulation of Influence of Changing a Dam Height on Liquid Steel Flow and Behaviour of Non-metallic Inclusions in the Tundish

a)

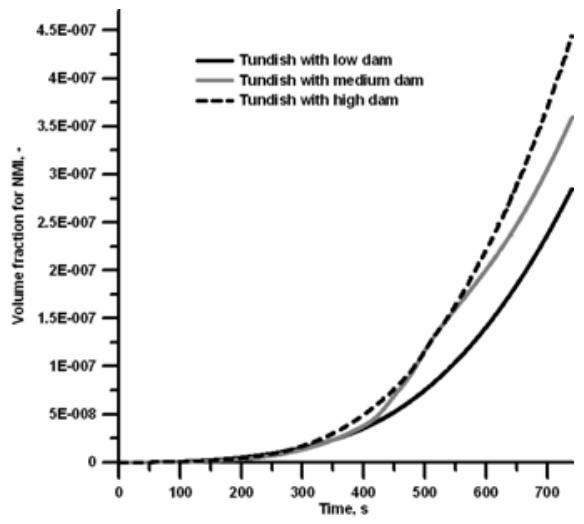

b)

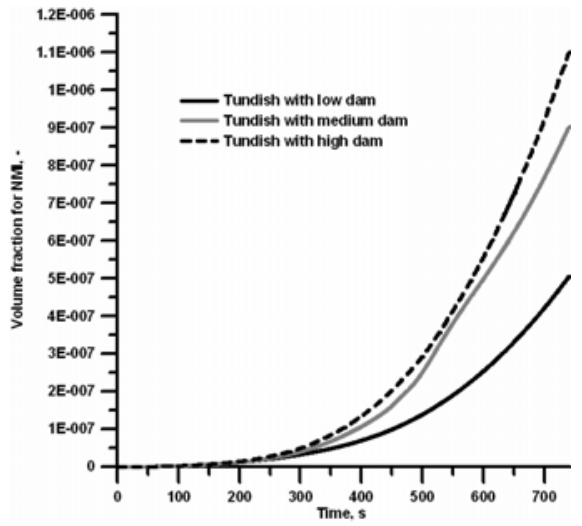

c)

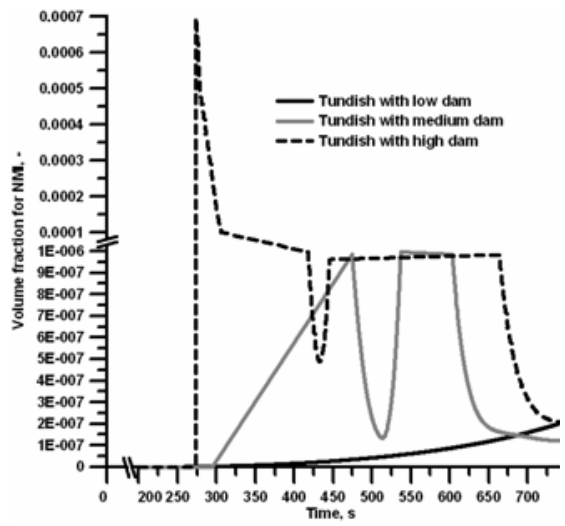

d)

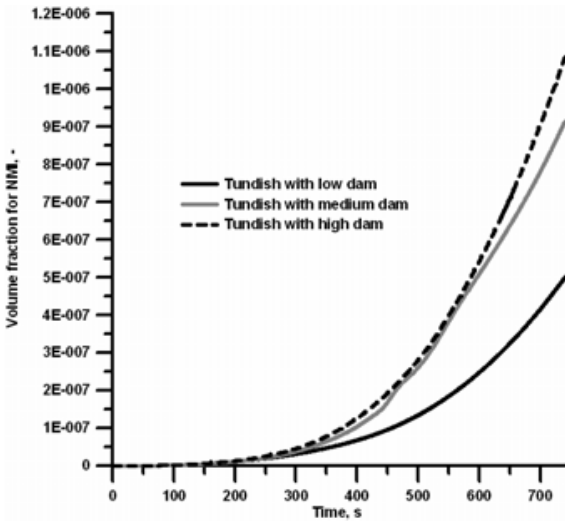

e)

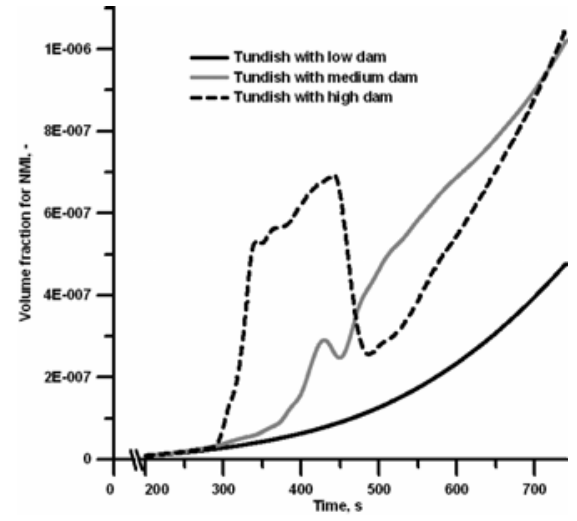

f)

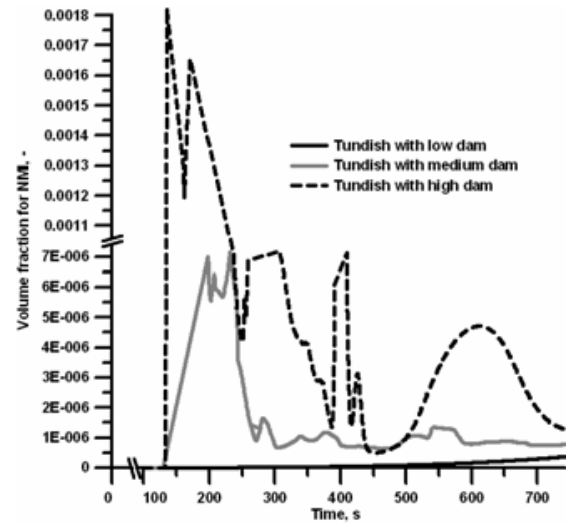

Fig. 15. NMI growth curve for 7,6 $\mu$ m diameter inclusions: a) point $1, b)$ point $2, \mathrm{c}$ ) point 3 , d) point 4 , e) point 5, f) tundish outlet 
a)

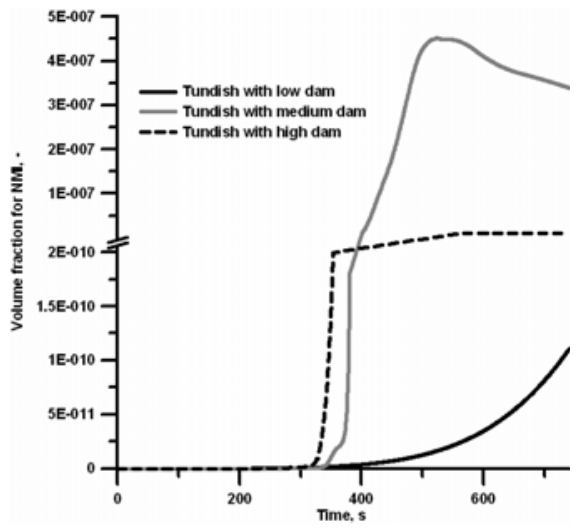

b)

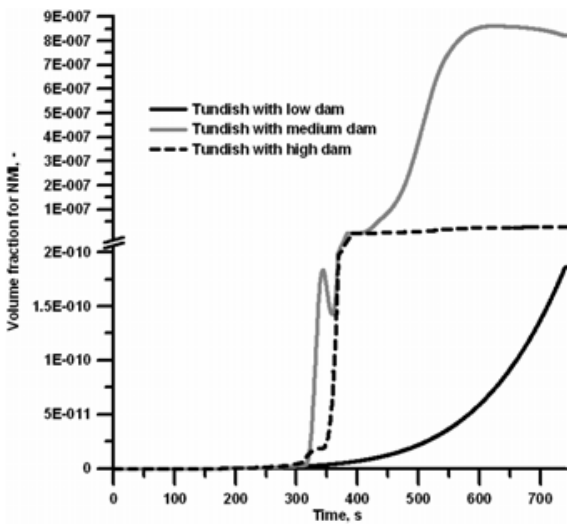

c)

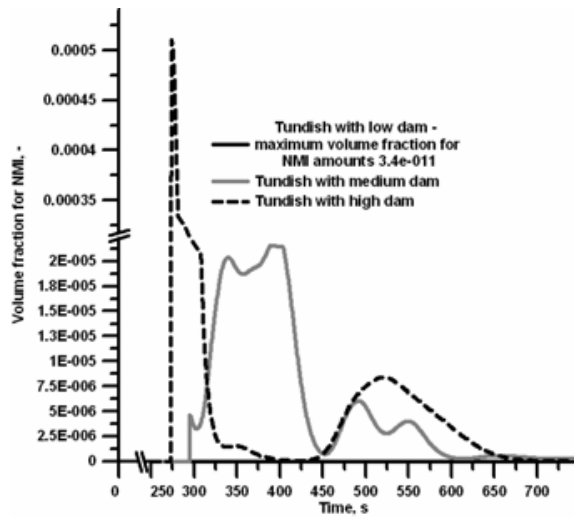

d)

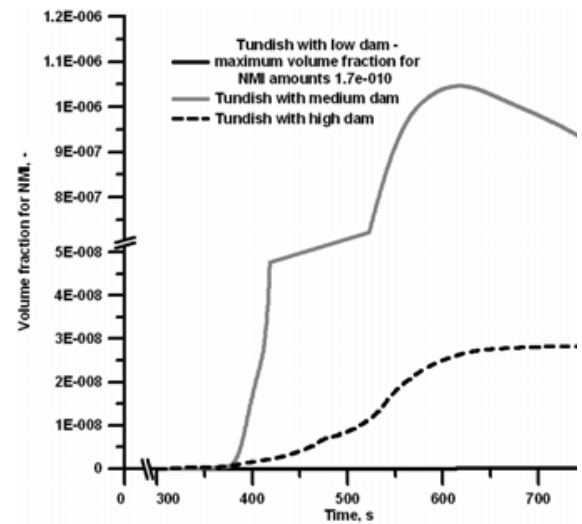

e)

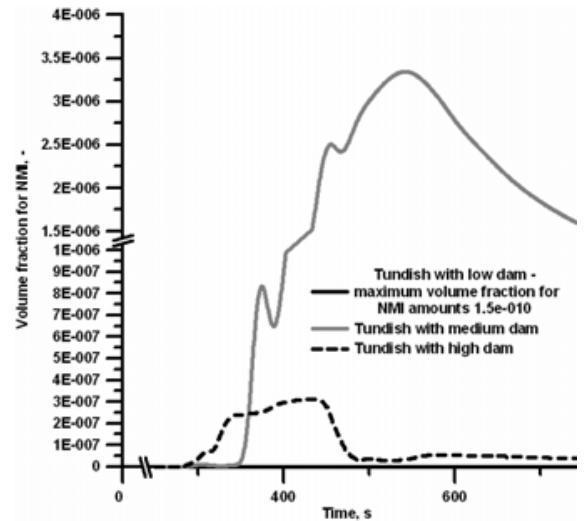

f)

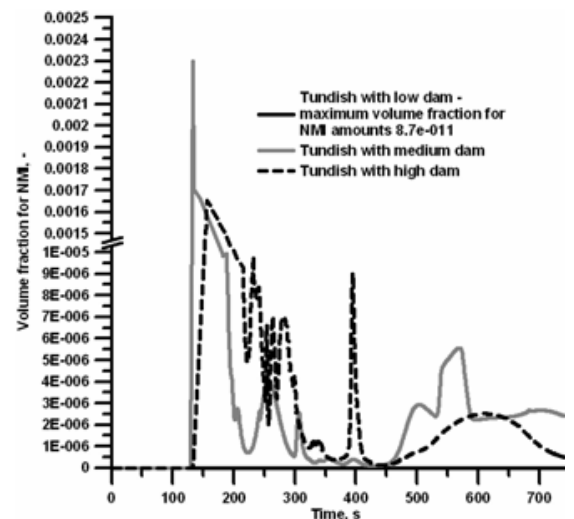

Fig. 16. NMI growth curve for $11 \mu$ m diameter inclusions: a) point $1, b)$ point $2, c)$ point 3 , d) point 4 , e) point 5, f) tundish outlet 


\section{Conclusion}

On the basis of the performed computations and industrial experiments it has been established that:

- The numerical steel flow model correctly reflects the hydrodynamic conditions of steel flow in the tundish,

- The numerical NMI growth model, in spite of the lack of satisfactory agreement with the industrial experiment results, can be used for the preliminary analysis of the influence of flow control devices on the NMI growth process,

- Increasing the dam height does not disturb the thermal stability of the tundish

- Raising the dam causes an increase in the plug flow share and a decrease in the stagnant flow share in the steel flow pattern,

- By changing the dam height, the extent of the transient zone between steel grades of different chemical composition being cast is reduced.

- The proposed upgrade of the dam will intensify the process of NMI growth in the tundish.

\section{Acknowledgment}

This scientific work has been financed from the resources allocated for Science in the years 2009-2011 as Research Project No. N508390437.

This publication has been made with the financial support by the Foundation for Polish Science

\section{References}

Basu, S.; Choudhary, S. K. \& Girase N. U. (2004). Nozzle clogging bahaviour of Ti-bearing Al-killed ultra low carbon steel. ISIJ International, Vol.44, No.10, pp. 1653-1660, online ISSN 1347-5460

Bessho, N.; Yamasaki, H.; Fujii, T.; Nozaki, T. \& Hiwasa, S. (1992). Removal of inclusion from molten steel in continuous casting tundish. ISIJ International, Vol.32, No.1, pp. 157-163, online ISSN 1347-5460

Clark, M.; Wagner, T. \& Trousset, A. Modeling for tundish applications, 01.2008, Available from http://www.foseco-steel.com/steel/downloads/technical_papers/08.pdf

Cwudziński, A. (2008). Control of steel flow in the slab tundish, PhD Thesis, Czestochowa University of Technology. (in polish)

Cwudziński, A. (2010). Numerical simulation of liquid steel flow and behaviour of nonmetallic inclusions in one-strand slab tundish with subflux turbulence controller and gas permeable barrier. Ironmaking \& Steelmaking, Vol.37, No.3, pp. 169-180, online ISSN 1743-2812

Gupta, N. \& Chandra S. (2004). Temperature prediction model for controlling casting superheat temperature. ISIJ International, Vol.44, No.9, pp. 1517-1526, online ISSN 1347-5460

Herrera-Trejo, M.; Castro, M. R.; DMendez, J. N.; Solis, H. T.; Tena, J. M. \& Guzman, E. (1998). Evolution of inclusion nature during the EAF-LF-CC process. Scandinavian Journal of Metallurgy, Vol.27, pp. 233-239, ISSN 0371-0459 
Hou, Q.; Yue, Q.; Wang, H.; Zou, Z. \& Yu, A. (2008). Modelling of inclusion motion and flow patterns in swirling flow tundishes with symmetrical and asymmetrical structures. ISIJ International, Vol.48, No.6, pp. 787-792, online ISSN 1347-5460

Ilegbusi, O.; Iguchi, M. \& Wahnsiedler, W. (2000). Mathematical and Physical Modeling of Materials Processing Operations, Chapman \& Hall/CRC, ISBN 9781584880172

Kuklev, A. V.; Tinyakov, V. V.; Aizin, Y. M.; Gushchin V. N.; Ul'yanin V. A.; Ordin, V. G.; Lamukhin, A. M. \& Zagorul'ko V. P. (2004). Optimization of the hydrodynamic characteristics of tundishes in order to remove exogeneous nonmetallic inclusions. Metallurgist, Vol.48, No.3-4, pp. 153-157, online ISSN 1573-8892

Lachmund, H. \& Xie, Y. (2003). High purity steels: a challenge to improved steelmaking processes. Ironmaking \& Steelmaking, Vol.30, No.2, pp. 125-129, online ISSN 17432812

Lopez-Ramirez, S.; Barreto, J. de J.; Palafox-Ramos, J.; Morales, R. D. \& Zacharias D. (2001). Modeling study of the influence of turbulence inhibitors on the molten steel flow, tracer dispersion and inclusion trajectories in tundishes. Metallurgical and Materials Transactions B, Vol.32, August, pp. 615-627, ISSN 1073-5615

Matsuura, H.; Wang, C.; Wen, G. \& Sridhar S. (2007). The transient stages of incluion evolution during $\mathrm{Al}$ and/or Ti additions to molten iron. ISIJ International, Vol.47, No.9, pp. 1265-1274, online ISSN 1347-5460

Mazumdar, D. \& Guthrie, R. I. L. (1999). The Physical and Mathematical Modelling of Continuous Casting Tundish Systems. ISIJ International, Vol.39, No.6, pp. 524-547, online ISSN 1347-5460

Nuspl, M.; Wegscheider, W.; Dekkers, R.; Angeli, J.; Posch, W. \& Mayr, M. (2004). Qualitative and quantitative determination of micro-inclusions by automated SEM/EDX analysis. Analitycal and Bioanalytical Chemistry, Vol.379, No.4, pp. 640645 , online ISSN 1618-2650

Rocabois, P.; Lehmann, J.; Gatellier, C. \& Teres, J. P. (2003). Non-metallic incluions entrapment by slags: laboratory investigation. Ironmaking $\mathcal{E}$ Steelmaking, Vol.30, No.2, pp. 95-100, ONLINE ISSN 1743-2812

Sahai, Y. \& Emi, T. (1996). Melt Flow Characterization in Continuous Casting Tundishes. ISIJ International, Vol.36, No.6, pp. 667-672, online ISSN 1347-5460

Solorio-Diaz, G.; Morales, R. D.; Palafox-Ramos, J. \& Ramos-Banmderas, A. (2005). Modeling the effects of a swirling flow on temperature stratification of liquid steel and flotation of inclusions in a tundish. ISIJ International, Vol.45, No.8, pp. 1129-1137, online ISSN 1347-5460

Tanaka, H.; Nishihara, R.; Miura, R.; Tsujino, R.; Kimura, T.; Nishi, T. \& Imoto T. (1994). Technology for Cleaning of molten steel in tundish. ISIJ International, Vol.34, No.11, pp. 868-875, online ISSN 1347-5460

Van Ende, M-A.; Guo, M.; Dekkers, R.; Burty, M.; Van Dyck, J.; Jones P. T.; Blanpain, B. \& Wollants, P. (2009). Formation and evolution of Al-Ti oxide inclusions during secondary steel refining. ISIJ International, Vol.49, No.8, pp. 1133-1140, online ISSN 1347-5460

Xie, D.; Garlick C. \& Tran, T. (2005). The wear of tundish stopper refractories by inclusion slags. ISIJ International, Vol.45, No.2, pp. 175-182, online ISSN 1347-5460 


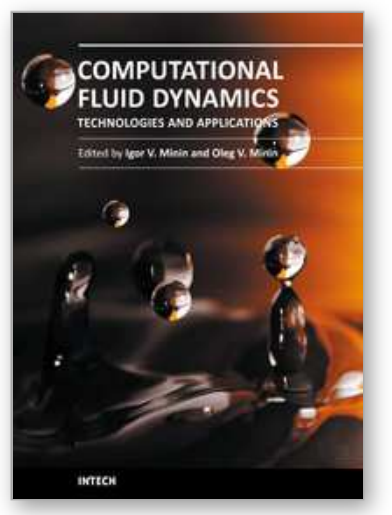

\section{Computational Fluid Dynamics Technologies and Applications}

Edited by Prof. Igor Minin

ISBN 978-953-307-169-5

Hard cover, 396 pages

Publisher InTech

Published online 05, July, 2011

Published in print edition July, 2011

This book is planned to publish with an objective to provide a state-of-art reference book in the area of computational fluid dynamics for CFD engineers, scientists, applied physicists and post-graduate students. Also the aim of the book is the continuous and timely dissemination of new and innovative CFD research and developments. This reference book is a collection of 14 chapters characterized in 4 parts: modern principles of CFD, CFD in physics, industrial and in castle. This book provides a comprehensive overview of the computational experiment technology, numerical simulation of the hydrodynamics and heat transfer processes in a two dimensional gas, application of lattice Boltzmann method in heat transfer and fluid flow, etc. Several interesting applications area are also discusses in the book like underwater vehicle propeller, the flow behavior in gas-cooled nuclear reactors, simulation odour dispersion around windbreaks and so on.

\section{How to reference}

In order to correctly reference this scholarly work, feel free to copy and paste the following:

Adam Cwudzinski (2011). Numerical Simulation of Influence of Changing a Dam Height on Liquid Steel Flow and Behaviour of Non-metallic Inclusions in the Tundish, Computational Fluid Dynamics Technologies and Applications, Prof. Igor Minin (Ed.), ISBN: 978-953-307-169-5, InTech, Available from:

http://www.intechopen.com/books/computational-fluid-dynamics-technologies-and-applications/numericalsimulation-of-influence-of-changing-a-dam-height-on-liquid-steel-flow-and-behaviour-of-non

\section{INTECH}

open science | open minds

\section{InTech Europe}

University Campus STeP Ri

Slavka Krautzeka 83/A

51000 Rijeka, Croatia

Phone: +385 (51) 770447

Fax: +385 (51) 686166

www.intechopen.com

\section{InTech China}

Unit 405, Office Block, Hotel Equatorial Shanghai

No.65, Yan An Road (West), Shanghai, 200040, China

中国上海市延安西路65号上海国际贵都大饭店办公楼 405 单元

Phone: +86-21-62489820

Fax: $+86-21-62489821$ 
(C) 2011 The Author(s). Licensee IntechOpen. This chapter is distributed under the terms of the Creative Commons Attribution-NonCommercialShareAlike-3.0 License, which permits use, distribution and reproduction for non-commercial purposes, provided the original is properly cited and derivative works building on this content are distributed under the same license. 